\title{
EVALUATION OF LAND SURFACE TEMPERATURE PARAMETERIZATION APPROACHES USING SURFACE- LAYER OBSERVATIONS
}

\author{
R. T. Akinnubi ${ }^{1}{ }^{*}$, and M. O. Adeniyi ${ }^{2}$ \\ 1 Department of Physics, Adeyemi College of Education, Ondo, Ondo State NiGERIA \\ 2 Department of Physics, University of IBADAN, IBADAN, Oyo STATE, NIGERIA. \\ E-mail addresses: ${ }^{1}$ rufus782000@yahoo.com, ${ }^{2}$ mojisolaadeniyi@yahoo.com
}

\begin{abstract}
Surface temperature $\left(T_{s}\right)$ is vital to the study of land-atmosphere interactions and climate variabilities. However, observed $T_{s}$ data are still very scarce in humid tropical region. There is therefore a need to parameterize and improve the representation of $T_{s}$ in Global Climate Models using available meteorological data. Six land surface temperature parameterization approaches (Force restored, Liebethal, Holtslag, Equilibrium Gradient, Tracy and Gottsche approaches) were validated with actual measurements using the Nigeria Micrometeorological Experiment (NIMEX) surface layer observations. The Liebethal approach showed the best agreement with the measured data with average coefficient of determination, mean bias error and root mean square error of $0.96 \pm 0.01,0.08 \pm 0.04^{\circ} \mathrm{C}$ and $0.85 \pm 0.14^{\circ} \mathrm{C}$, respectively, in simulated $T_{s}$. The results also showed that the Force restored and Tracy approaches are applicable for land surface temperature parameterization in this region.
\end{abstract}

Keywords: Surface Temperature, Climate Change, Humid, Parameterization, Mean Bias Error

\section{INTRODUCTION}

Surface temperature $\left(T_{s}\right)$ is needed in the computation of the turbulent heat fluxes as well as the terrestrial radiation in weather and climate studies [1-2]. It is also important to understand that the diurnal variation of $T_{s}$ constitute one of the principal indicators of climate change[3-7].Despite the vital importance of diurnal $T_{s}$ data in computation of heat fluxes, they are still not available in most synoptic stations over West Africa. There is therefore a need to parameterize, assess and improve the representation of $T_{s}$ in weather and climate simulations [8-10] because bias is expected from parameterizations.

Several surface layer parameterization approaches have been employed to parameterize surface temperature using diurnal data in arid and semi arid regions, some of them use only atmospheric information while others require measurements in the soil. They all validated their parameterization approaches using measured data from the specific regions. For instance, the Equilibrium Gradient approach (Lucre and Tarbortan, [11], hereinafter referred to as EG) and Holtslag approach (Holtslag, [12], hereinafter referred to as HA), have been widely used in weather forecasting models, Idso et al. [13]. Smith approach (Smith and Blackall, [14], SM) has been used in a land surface model to estimate surface temperature [15]. Also, the Liebethal approach (LI) was derived from energy balance experiments using soil temperature measurement at two depths [14]. Tracy approach (Tracy et al., [16], TR) assumed constant emissivity in the estimate of surface temperature using energy budget theory. Gao et al. [17] introduced the details of Force-Restore approach (FR) and had been incorporated in a land data assimilation system of arid and semi-arid regions. Gottsche and Olesen [18] developed semi-empirical diurnal temperature cycle approach (GO) using maximum and minimum daily $T_{s \text {. }}$ The implementation of this GO approach may face some difficulties in this region, because daily $T_{s}$ data are not readily available. Adeniyi and Nymp has [19] estimated surface temperature from soil temperature measured at $5 \mathrm{~cm}$ depth and also from $1 \mathrm{~m}$ air temperature using regression analysis.

Most of the above mentioned existing $T_{s}$ parameterization approaches have not been validated over West Africa. Nigerian Micrometeorological Experiment (NIMEX) is one of the few experiments over West Africa which provides direct measurement of land surface temperature and other climate data at various time intervals of interest [20-22]. With the NIMEX data, it is possible to implement and validate some of the above mentioned surface temperature parameterization approaches in the tropics. This paper therefore aims at

\footnotetext{
* Corresponding author tel: $+234-803-462-2265$
} 
evaluating the performance of six existing $T_{S}$ parameterization approaches.

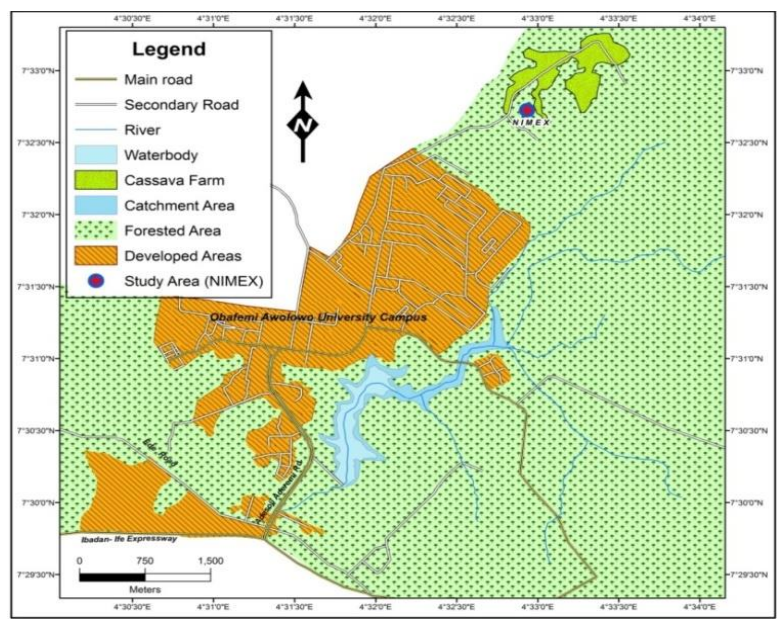

Fig. 1: Map showing the position of the measurement site (Ile-Ife) in Nigeria.

\section{MATERIAL AND METHODS}

\subsection{Experimental Site and Methodology}

Nigeria Micrometeorological Experiment (NIMEX) [20] was conducted at Ile Ife, Nigeria (Latitude $7^{0} 33^{\prime} \mathrm{N}$ and longitude $4^{0} 33^{\prime} \mathrm{E}$ ) during the transition period from dry to wet season (Fig. 1). The period of intensive observation was from 19th February to $9^{\text {th }}$ March, Day of the year (DOY) (DOYs 55-70) in 2004. This site is located in the humid equatorial region of West Africa and the climatic region is Aw class according to Köppen classification [23]. This site is at the attitude of $288 \mathrm{~m}$ above sea level and its vegetation can be characterized as fallow bush-land [21]. The ground surface of the site is flat and homogenous. The soil is loamy sand and it is at its permanent wilting condition at the beginning of the experiment [20 -21]. The acquisition of data was achieved by using Campbell Scientific data logger systems (measurement and control module) approach CR10-X. The surface temperature was measured using Infrared thermometer (Heitronics) remotely sensing the ground at the height of $1.8 \mathrm{~m}$, with measurement accuracy of $\pm 1^{\circ} \mathrm{C}$ and sampled every $1 \mathrm{~s}$ (averaged to produce $10 \mathrm{~min}$ and $30 \mathrm{~min}$ statistics). Simple visual test according to Foken [24] was used on daily basis to check the quality of the basic meteorology variables (slow response). The maximum and minimum surface temperatures observed during the period of the experiment were $48.44^{\circ} \mathrm{C}$ and $32.54^{\circ} \mathrm{C}$ respectively.The annual rainfall amount is $1225 \mathrm{~mm}$ [25].

\subsection{Surface Temperature Parameterization Approaches}

The selected $T_{s}$ parameterization approaches are the Force-Restored Approach (FR), the Equilibrium Gradient Approach (EG), Holtslag Approach (HA), Liebethal Approach (LI), Gottsche approach (GO) and Tracy approach (TR). The working principles and mathematical expressions of these $T_{s}$ parameterizations are tabulated in Table 1.0. The six selected parameterizations are quite demanding in terms of data requirement and the implementations, and some of the input data are not available in routine synoptic stations. However, they are all available in NIMEX data set. Also, their algorithms are widely applied [11-19], and their good performances in other regions are well documented. These $T_{s}$ parameterizations are yet to be fully explored in this region.

The FR and EG parameterizations require the estimation of the optimal depth which was found to be $0.0700 \mathrm{~m}$, from the NIMEX data; this value has a close agreement with the $0.0853 \mathrm{~m}$ given by Stull [26]. Also, the assumption of a constant value of $p$ in the EG expression for ground heat flux $Q_{g}\left(Q_{g}=p Q_{s}\right.$, where $Q_{s}$ is the net radiation and $\mathrm{p}$ is taken as 0.3 ) gave a large error. To minimize this error, the measured $Q_{g}$ was used in EG parameterization. The $\mathrm{HA}$ resulted in numerical instabilities in stable (neutral) conditions. To solve this problem, stability correction according to Richardson number was included in the parameterizations for both stable and unstable atmospheric conditions. LI calculates $T_{S}$ from the ranges of soil temperature $T_{1}$ and $T_{2}$ at the depths, $z_{1}(5 \mathrm{~cm})$ and $z_{2}(10 \mathrm{~cm})$. Though, the approach was originally formulated for only the daytime parameterization of $T_{s}$, it was tested for both unstable and stable conditions, since data are available for whole day. Tracy approach was used to estimate $T_{S}$ under steady state condition, since neutral condition is very rare in this part of the tropics. The convection transfer coefficients for different surfaces were calculated under different atmospheric conditions. In G.O., the attenuation constant was derived by making the first derivatives of the two functions ( $T_{\text {day }}$ and $T_{\text {night }}$ ) equal at the tropicals unset time $t_{s}$ (Table 1).

To evaluate the accuracy of different surface temperature parameterization approaches, their results are compared to the measured data using statistical means: Mean Bias Error $(M B E)$, Root Mean Square Error (RMSE) and coefficient of determination $\left(r^{2}\right)$. The $M B E$ is the average deviation between estimated and measured data. The RMSE is average positive distance between estimated and measured data. The MBE and RMSE are given as

$$
\begin{aligned}
M B E & =\sum_{i=1}^{n} \frac{\left(T_{S}(\text { Estimated })-T_{s}(\text { observed })\right.}{n} \\
R M S E & =\sqrt{\sum_{i=1}^{n} \frac{\left(T_{S}(\text { Estimated })-T_{S}(\text { observed })\right)^{2}}{n}}
\end{aligned}
$$

where $\mathrm{n}$ is the number of observation [27]. 
Table 1: Overview of the tested parameterization approaches: names and abbreviations of the approach, section in the text giving details on the approach

\begin{tabular}{|c|c|c|c|}
\hline Approach(s) & Expressions & Theories/assumptions & Reference(s) \\
\hline $\begin{array}{l}\text { The Force-Restored } \\
\text { Approach (FR) }\end{array}$ & $\left.T_{s}=T_{a}+A_{s} \exp \left(-\gamma_{a} z\right) \sin \left(\omega_{i}\left(j-j_{i}\right)-\gamma_{a} z\right]\right)$ & Thermal Diffusion Equation & [16] \\
\hline $\begin{array}{l}\text { The Equilibrium Gradient } \\
\text { Approach (EG) }\end{array}$ & $T_{s}=T_{a}+\frac{Q_{s} r d}{\lambda}$ & Thermal Diffusion Equation & [9] \\
\hline Holtslag Approach (HA) & $T_{s}=T_{a}+\frac{T_{*}}{\kappa}\left[\operatorname{In}\left(\frac{z_{2}}{z_{1}}\right)-\psi_{H}\left(\frac{z_{O H}}{L}\right)+\psi_{m}\left(\frac{z_{O m}}{L}\right)\right]$ & $\begin{array}{l}\text { Monin-Obukhov Similarities } \\
\text { Theory }\end{array}$ & [10] \\
\hline Liebethal approach(LI) & $T_{s}=T_{1}+T_{2} \exp \left(\frac{z_{2}}{z_{2}-z_{1}}\right)$ & Thermal Diffusion Equation & [14] \\
\hline Tracy Approach (TR) & $T_{s}=\frac{T_{a}+Q-K_{e}\left(h_{c} q_{2}^{*}-q_{1}\right)-\varepsilon \sigma T_{a}^{4}}{K_{e}+\lambda K_{e} s+4 \varepsilon \sigma T_{a}^{3}}$ & Surface Energy Budget Theory & [15] \\
\hline Gottsche Approach (GO) & $\begin{aligned} & T_{s}(\text { day })(t)= T_{o}+T_{a} \cos \left(\frac{\pi}{\omega}\left(t-t_{m}\right)\right) t<t_{s}, \\
& T_{s}(\text { night })(t)= T_{o}+T_{a} \cos \left(\frac{\pi}{\omega}\left(t-t_{m}\right)\right) e^{-\left(\frac{t-t_{s}}{k}\right)_{t}} \\
& \geq t_{s},\end{aligned}$ & $\begin{array}{l}\text { Thermal Diffusion Equation/ } \\
\text { Newton's Law Of Cooling }\end{array}$ & [17] \\
\hline
\end{tabular}

Meaning of symbols: Qs- Net Radiation, $A_{s}$ - Surface Amplitude, $T_{a}$ - Air Temperature, z- height of $T_{a}, \gamma_{a}$ - Damping Depth, $\omega_{i}$ - Angular Velocity, r-dimensionless parameter, $\lambda$ - effective distance, $\kappa$-Von Karma Constant, $z_{O H}$ - Roughness length due to heat transfer, $z_{O m}$ Roughness length due to momentum, L- Monin-Obukhov length, $T_{1}$ and $T_{2}$ - Soil Temperature at two different depths, $K_{e}-$ Convection Transfer Coefficient, $h_{c}-$ Humidity of the air in the equilibrium $q_{2}^{*}$ - saturated vapour density, $\varepsilon$ - emissivity $\sigma-$ Stefan-Boltzman constant, s-slope of the saturated vapour density function, $T_{o}$ maximum air temperature-, $t_{m}$-the time at which the temperature reaches its maximum $k$ - the attenuation constant, $t_{s}$ - starting time of the free attenuation, d- damping depth, $\psi_{H}$ and $\psi_{m}$ are universal stability functions for heat transfer and momentum respectively, $q_{1}-$ specific humidity.

\section{RESULTS AND DISCUSSION}

\subsection{Results of the Surface Temperature Parameterization} Approaches

The diurnal variations of the simulated surface temperature $\left(T_{S}\right)$ as compared with measured data for wet and dry days are represented by Figs. $2 \mathrm{a}$ and $\mathrm{b}$ respectively. The period of investigation was characterized by weak wind $\left(<3.0 \mathrm{~ms}^{-1}\right)$ and the results of the validated $T_{s}$ parameterizations for this site presented in Figs. $2 \mathrm{a}$ and $\mathrm{b}$ can be summarized as follows.

The EG strongly underestimated the measured $T_{s}$ during the early hours of the morning by $5^{\circ} \mathrm{C}$ to $6^{\circ} \mathrm{C}$ and night period $\left(5^{\circ} \mathrm{C}\right.$ to $\left.8^{\circ} \mathrm{C}\right)$, while it overestimated it slightly $\left(2^{\circ} \mathrm{C}\right.$ to $3^{\circ} \mathrm{C}$ ) during the mid-day hours for wet days (Fig. 3a). The same pattern was estimated for dry days except for the large overestimation of about $9^{\circ} \mathrm{C}$ to $10^{\circ} \mathrm{C}$ (Fig. 2 b) during the mid-day hours. It could be deduced that EG favoured mid-day $T_{s}$ parameterization during the wet days than dry days. In other word, the EG might not be suitable for mid-day $T_{s}$ simulations for dry days. The large overestimation and underestimation in simulated $T_{s}$ during the transition period from dry to wet days could be attributed to the change in the diurnal values of soil moisture which was very high for wet days (mean value $=0.167 \mathrm{~m}^{3} \mathrm{~m}^{-3}$ ), and very low for dry days (mean value $\left.=0.049 \mathrm{~m}^{3} \mathrm{~m}^{-3}\right)$. The effective depth $\left(Z_{E}\right)$ in the EG parameterization varies with time and space, and is affected by soil type, structure and meteorological conditions. The HA strongly underestimated $T_{S_{s}}$ during the early hours of the morning (about $7^{\circ} \mathrm{C} \sim 10^{\circ} \mathrm{C}$ ), during the mid-day hours $\left(10^{\circ} \mathrm{C} \sim 15^{\circ} \mathrm{C}\right)$ and during the night-time hours $\left(10^{\circ} \mathrm{C}\right.$ to $\left.25^{\circ} \mathrm{C}\right)$ for both wet and dry days (Fig. 2a and b). These findings revealed the poor performance of HA in $T_{s}$ parameterization for both wet and dry days. It could also be deduced that HA simulation does not favour tropical atmosphere condition especially area where low-wind speed is prevalent.

The GO slightly underestimated $T_{s}$ during the early hours of the morning (about $4^{\circ} \mathrm{C}$ to $8^{\circ} \mathrm{C}$ ), and slightly overestimated it (about $2^{\circ} \mathrm{C}$ to $3^{\circ} \mathrm{C}$ ) for mid-day period for both wet and dry days (Figs $2 \mathrm{a}$ and $\mathrm{b}$ ). The night time simulated $T_{s}$ value showed good agreement with the measured data, though a slight underestimation was observed for DOY 57. Generally, the performance of the GO approach was consistent for stable atmospheric 
condition during the transition from dry to wet periods. The findings also show, that GO might not be appropriate for the experimental site in this humid region, especially during daytime period. Also, the implementation of the GO might face some difficulties in the region because of the dearth of $T_{s}$ data from routine meteorological stations in this region.

The LI approach showed closeness to the measured data during daytime, with slight overestimation (about $1^{\circ} \mathrm{C}$ ) during the early hours of the morning for both wet and dry days respectively. The performance of LI also showed a strong agreement with the measured data during the mid-day hours. During the night-time, a slight overestimation of about $0.1^{\circ} \mathrm{C}$ to $0.2^{\circ} \mathrm{C}$ was also observed. Thus, LI performance was better when compared with other parameterizations. However, its implementation might be peculiar to experimental site with soil temperature data measured at two depths. In contrast to the LI approach, the TR simulated $T_{s}$ also had a better agreement with the measured data for early hours of the morning, with slight overestimation of about $0.7^{\circ} \mathrm{C}$ to $4.5^{\circ} \mathrm{C}$ for both wet and dry days. The performance of the TR during night-time was poor for both wet and dry periods with wet days having poorer performance. It could be deduced that TR would be suitable during the daytime for both wet and dry days. This implies that the behaviour of TR is affected by some meteorological conditions during the transition period. The zero-surface water potential approximation (wet days) when solving for $T_{s}$ from the surface energy balance equation may also cause the overestimation during the night-time period. This assertion was confirmed by the findings of Campbell and Norman [28] and Monteith [29]. The inconsistency in the behaviour of TR during the transition period makes it unsuitable for use at the site. Furthermore, Figs $3 \mathrm{a}$ and $\mathrm{b}$ revealed that the daytime $T_{s}$ value from Forcerestored approach was underestimated by $2{ }^{\circ} \mathrm{C}$ to $3{ }^{\circ} \mathrm{C}$ for both wet days and dry days. It can be concluded that the FR approach reproduced the $T_{s}$ data very well for all conditions encountered during NIMEX, especially for unstable conditions. Lin [30] points out that the depth of the upper soil layer is essential for good results of $T_{s}$. And, in the course of the analysis, the optimal depth was found to be $0.0700 \mathrm{~m}$, which closely agreed with the $0.0853 \mathrm{~m}$ given by Stull [24].

The wet and dry composite comparisons of the measured surface temperature with simulated surface temperature using different $T_{s}$ parameterization at Ile-Ife site are illustrated in Fig. $3(a-b)$. The overall performance of some parameterizations like EG and HA showed large deviations from the measured data during the early hours of the morning and late hours of the night-time. The LI and FR yielded better results, with an average low bias during stable conditions. During the daytime, except for LI and FR, greater fitting errors were found around sunrise and noon. However, during early hours of the night-time, all the selected parameterizations except HA, described the diurnal pattern of variation of $T_{s}$.

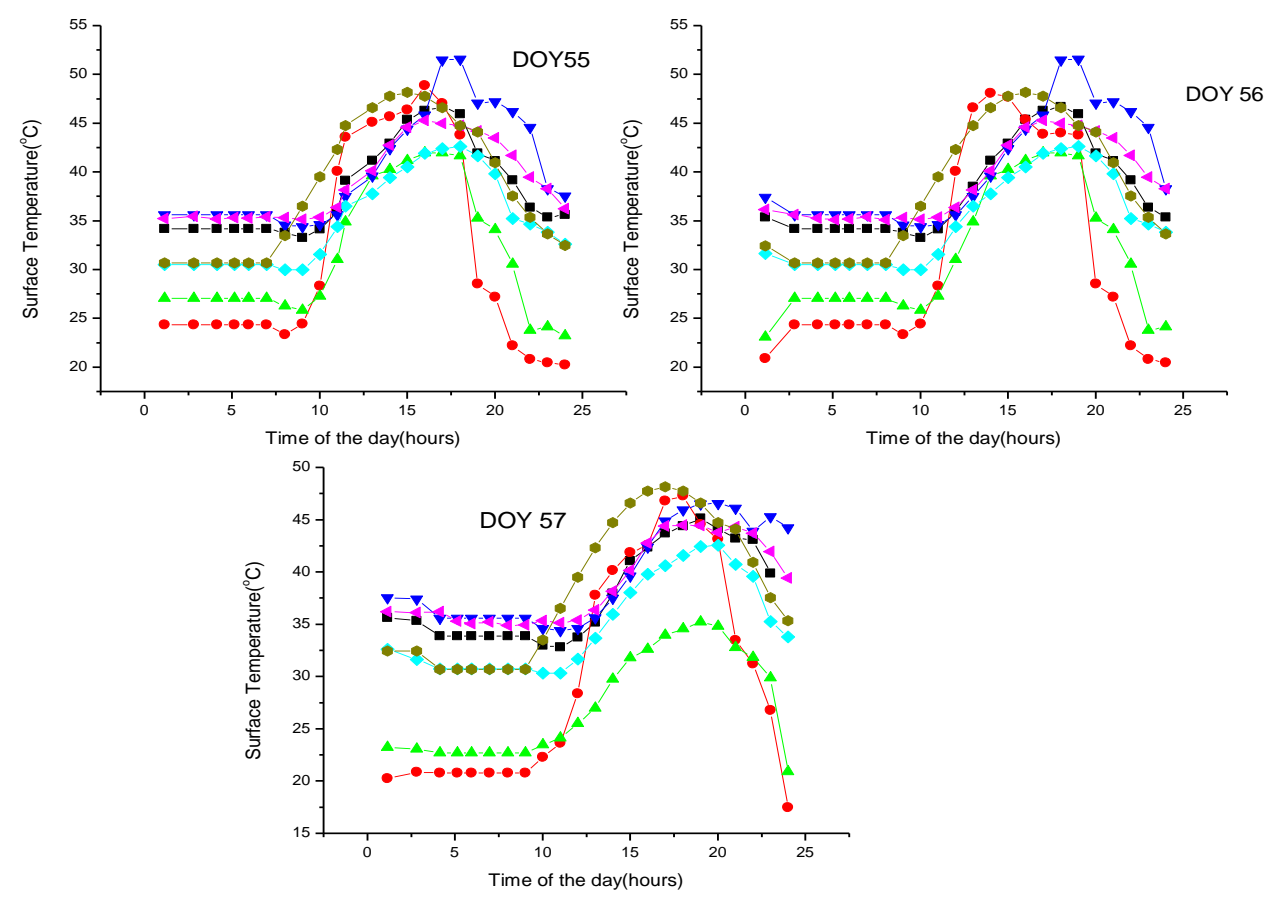

\footnotetext{
- Measured data —-Equlibrium gradient model $\_$- Holtlag model- $\nabla$ Tracy Model Force Restored model $\triangleleft$ Liebethal model —-Gottsche model
}

Fig. 2 (a): Comparison of measured surface temperature with approached surface temperature using different approaches at Ile-Ife site on DOYs 55 - 57 (Wet Days), 2004. 


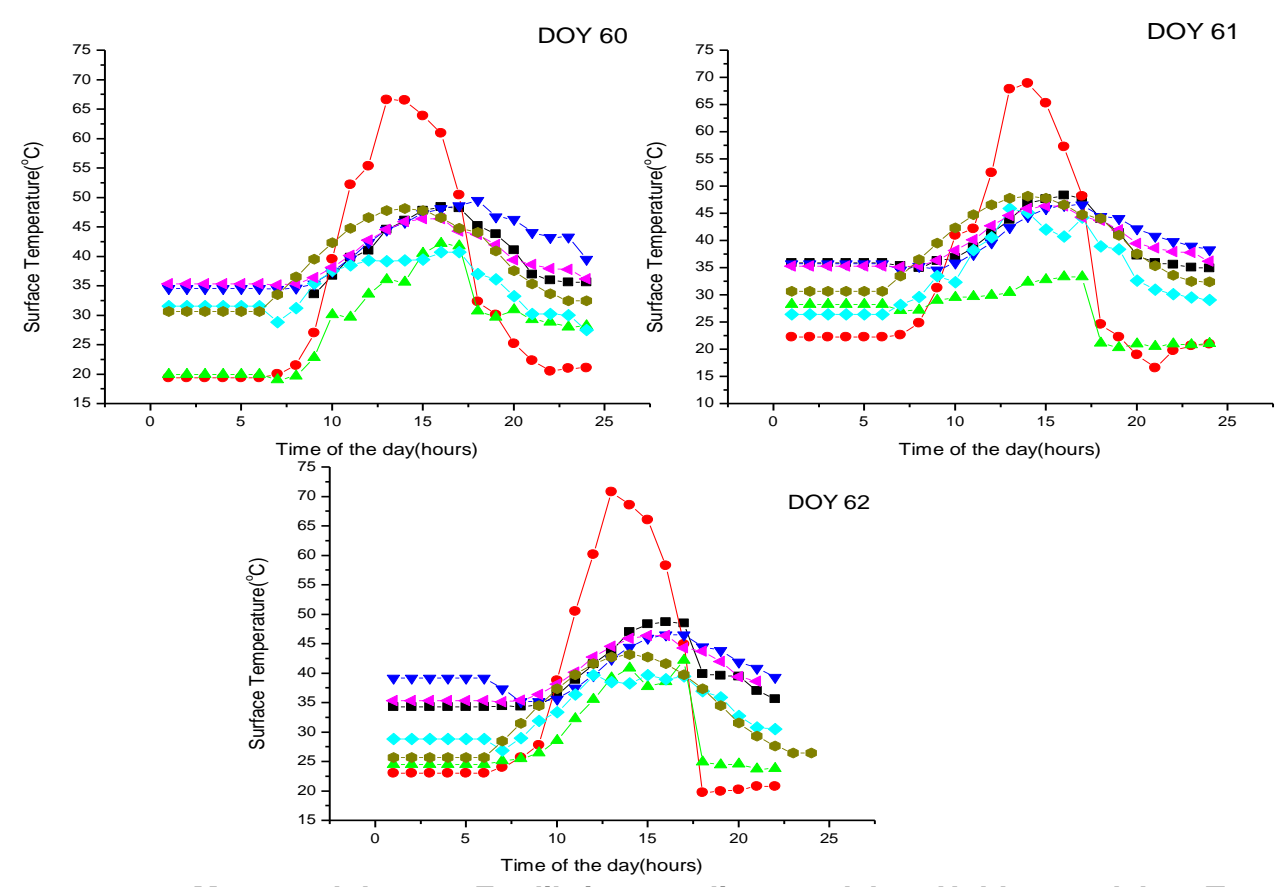

- Measured data-Equlibrium gradient model - Holtlag model- $\nabla$ Tracy Model
Force Restored model 4 Liebethal model-Gottsche model

Fig. 2 (b) Comparison of measured surface temperature with approached surface temperature using different approaches at Ile-Ife site on DOYs 60 - 62 (Dry Days), 2004.

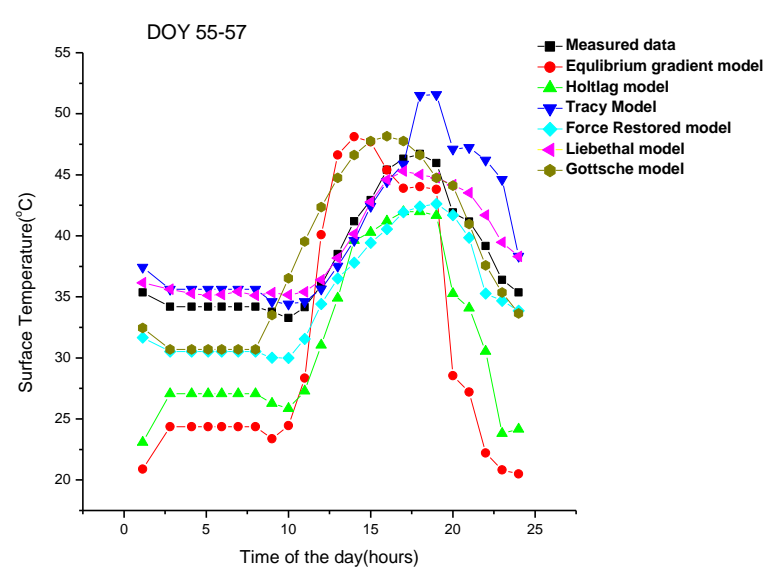

Fig. 3 (a): Composite Comparison of measured surface temperature with approached surface temperature using different approaches at Ile-Ife site on DOYs 55 - 57 (Wet Days), 2004.

\subsection{Evaluation of the Performance of the Surface} Temperature Parameterization Approaches

The scatter plots showing the simulated surface temperature versus the measured data for Ile-Ife site are shown in Fig. 4. The scatter from EG were considerably large (Fig. 4). This revealed partly strong overestimations for large values of $T_{S}$ during the mid-day hours. The MBE values of $-4.04^{\circ} \mathrm{C}$ and $-6.28^{\circ} \mathrm{C}$ respectively for wet and dry days revealed strong underestimations for small value of $T_{S}$ for early hours of

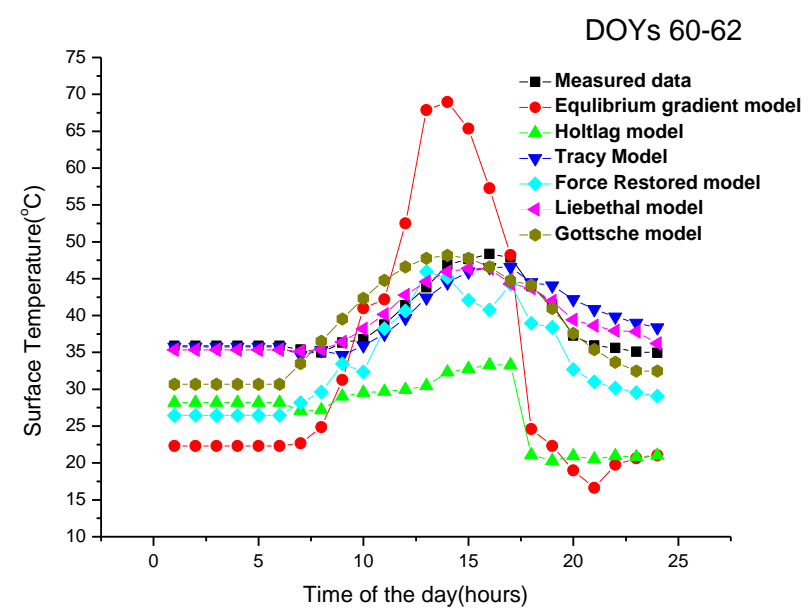

Figure 3 (b): Composite Comparison of measured surface temperature with approached surface temperature using different approaches at Ile-Ife site on DOYs 60-62 (Dry Days), 2004.

the morning and late hours of the night-time, and large values of RMSE were also obtained for both unstable $\left(7.15^{\circ} \mathrm{C} \sim 14.12^{\circ} \mathrm{C}\right)$ and stable $\left(7.61^{\circ} \mathrm{C} \sim 11.43^{\circ} \mathrm{C}\right)$ conditions during both wet and dry days. This was also confirmed by the amount of scatter seen in Figure. 4 a. the advantage of the EG is that it requires only few input data. However, this was outweighed by large discrepancies between the measured and simulated parameters. For HA, the scatter and RMSEs $\left(3.50^{\circ} \mathrm{C} \sim\right.$ $4.26^{\circ} \mathrm{C}$ for unstable condition; $1.71^{\circ} \mathrm{C} \sim 3.83^{\circ} \mathrm{C}$ for stable 
condition) are remarkable large, and the MBE values ($0.17^{\circ} \mathrm{C} \sim 0.32^{\circ} \mathrm{C}$ ) revealed strong underestimations for stable and unstable conditions, but the average $r^{2}$ values were high $(0.65 \sim 0.78)$.

Furthermore, for GO, the findings revealed that the scatter $\left(r^{2} \sim 0.56\right)$ was relatively large with outliers along the regression line (Fig. $4 \mathrm{f}$ ). The average RMSE ranged from $1.05^{\circ} \mathrm{C}$ to $8.69^{\circ} \mathrm{C}$ for wet and dry days respectively. There was high $r^{2}$ between the observed and estimated $T_{S}$, despite the observed large scatters for night-time $T_{S}$ parameterization for dry days $\left(r^{2} \sim 0.30\right)$. For LI approach, the scatter was relative small, with average $r^{2}$ values ranging from 0.67 to 0.95 for both unstable and stable atmospheric conditions. The RMSEs $\left(0.71{ }^{\circ} \mathrm{C} \sim\right.$ $1.58^{\circ} \mathrm{C}$ ) were of medium size compared to the other parameterizations. The negative MBE values $\left(-0.01^{\circ} \mathrm{C} \sim\right.$ $0.05^{\circ} \mathrm{C}$ ) showed a slight underestimation for small value of $T_{s}$. The LI showed a good agreement with the measured data (The average of $r^{2}$, MBE and RMSE in simulated $T_{s}$ were $0.96 \pm 0.01,0.08 \pm 0.04^{\circ} \mathrm{C}$ and $0.85 \pm$ $0.14^{\circ} \mathrm{C}$ respectively)

The TR approach had large scatter, with $r^{2}$ values ranging from 0.63 to 0.68 for wet and dry days respectively. A slight underestimation was observed for large values of $T_{s} \quad\left(\mathrm{MBE} \cong-0.02{ }^{\circ} \mathrm{C}--0.04^{\circ} \mathrm{C}\right)$. The daytime $T_{s}$ parameterization evidently improves the linear regression and the statistics of the TR. However, this does not remove the fact that the night-time $T_{s}$ parameterization is still poor ( $r^{2}$ values ranging from 0.02 to 0.24 ), with RMSEs ranging from $3.12^{\circ} \mathrm{C}$ to $3.90^{\circ} \mathrm{C}$ respectively. Obviously, the influence of the ambient conditions on night-time $T_{s}$ and variation of metrological condition from night to night might constitute to the poor performance at night-time.

The FR had a small scatter and for the 24 hrs version of approach, the MBE values ranged from $-0.05^{\circ} \mathrm{C}$ to -0.08 ${ }^{0} \mathrm{C}$, indicating a slight underestimation for small values of $T_{s}$ during the early and late hours of the day. The low RMSEs obtained ranged from $0.68^{\circ} \mathrm{C}$ to $2.16^{\circ} \mathrm{C}$, with high $r^{2}$ values ranging from 0.68 to 0.88 for daytime period, and low $r^{2}$ values of 0.41 to 0.44 for night-time period. It could be deduced that the FR did not favour the nighttime simulation especially during dry days, despite its small scatter.

\section{CONCLUSION}

Six different documented parameterization approaches that calculate land surface temperature have been tested over a bare soil surface to evaluate their performance in order to determine the best approach for use at the humid tropical region. Findings revealed that, the Liebethal approach has the best performance over this region. The Liebethal approach gave high value of coefficient of determination and least error values between measured and estimated surface temperature. The work also suggests that some parameterization approaches like Force restored and Tracy approaches are also suitable for the land surface parameterisation in this region, though their operational principles may be quite demanding in terms of data requirement and implementation.

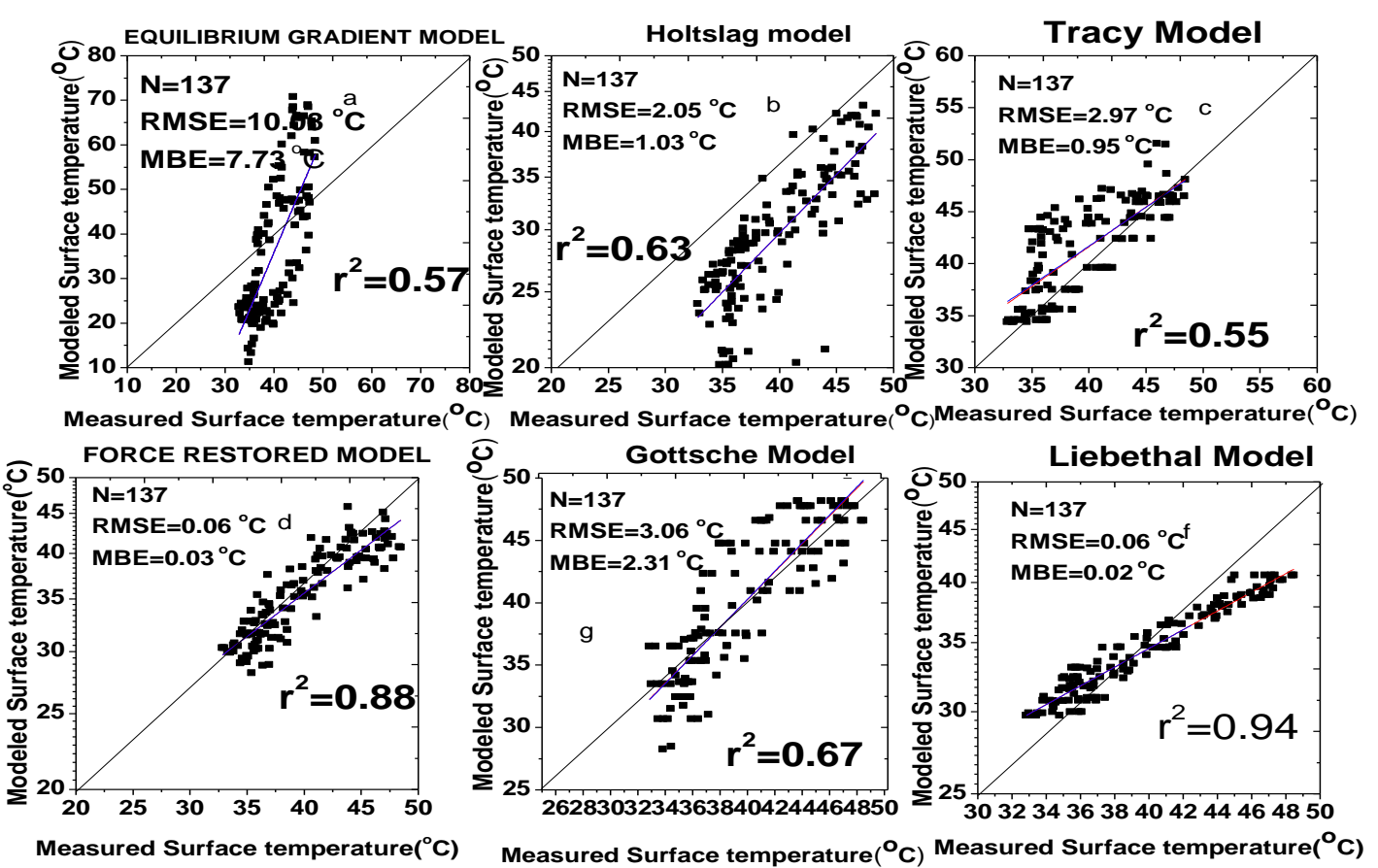

Fig. 4: Scatter plots showing the approached surface temperature vs the measured data for DOYs 55-70, 2004. 
Table 2 a: Parameters of the linear regression (slope a, intercept $b$ and coefficient of determination. $r^{2}$ ) as well as MBE and RMSE for the tested parameterization approaches with respect to the measured values for wet periods and dry period, DOYS 55-70, 2004

\begin{tabular}{|c|c|c|c|c|c|c|c|}
\hline Parameterization Approaches & Parameter & $\begin{array}{c}\text { Unstable } \\
\text { Period (Wet) }\end{array}$ & $\begin{array}{c}\text { Stable Period } \\
\text { (Wet) }\end{array}$ & $\begin{array}{c}\text { Full- Day } \\
\text { (Wet) }\end{array}$ & Stable Period(Dry) & $\begin{array}{c}\text { Unstable } \\
\text { Period(Dry) }\end{array}$ & $\begin{array}{c}\text { Full- Day } \\
\text { (Dry) }\end{array}$ \\
\hline $\begin{array}{l}\text { EQUILIBRIUM GRADIENT } \\
\text { APPROACH(EQ) }\end{array}$ & $\begin{array}{l}\text { a- best-fit slope } \\
\text { b- intercept } \\
\text { best-fit }-r^{2} \\
\text { MBE }\left({ }^{\circ} \mathrm{C}\right) \\
\text { RMSE }\left({ }^{\circ} \mathrm{C}\right)\end{array}$ & $\begin{array}{c}1.40 \\
-13.60 \\
0.56 \\
-4.04 \\
7.16 \\
\end{array}$ & $\begin{array}{c}2.04 \\
-48.31 \\
0.45 \\
-6.28 \\
7.61 \\
\end{array}$ & $\begin{array}{c}2.04 \\
-43.43 \\
0.56 \\
4.10 \\
11.16 \\
\end{array}$ & $\begin{array}{c}3.88 \\
114.00 \\
0.56 \\
-5.03 \\
14.12 \\
\end{array}$ & $\begin{array}{c}0.56 \\
2.59 \\
0.42 \\
5.44 \\
11.43 \\
\end{array}$ & $\begin{array}{c}3.71 \\
-108.11 \\
0.56 \\
3.03 \\
13.58 \\
\end{array}$ \\
\hline HOLTLAG APPROACH(HA) & $\begin{array}{l}\text { a- best-fit slope } \\
\text { b- intercept } \\
\text { best-fit }-r^{2} \\
\text { MBE }\left({ }^{\circ} \mathrm{C}\right) \\
\text { RMSE }\left({ }^{\circ} \mathrm{C}\right)\end{array}$ & $\begin{array}{c}0.92 \\
-2.89 \\
0.53 \\
-0.32 \\
4.26\end{array}$ & $\begin{array}{c}1.24 \\
-16.11 \\
0.24 \\
-0.34 \\
3.83\end{array}$ & $\begin{array}{c}1.17 \\
-13.17 \\
0.78 \\
-0.14 \\
3.56\end{array}$ & $\begin{array}{c}1.28 \\
-20.45 \\
0.67 \\
-0.13 \\
3.66\end{array}$ & $\begin{array}{c}1.42 \\
-24.77 \\
0.58 \\
-0.36 \\
1.71\end{array}$ & $\begin{array}{l}0.96 \\
-8.96 \\
0.65 \\
-0.17 \\
3.13\end{array}$ \\
\hline GOTTSCHE APPROACH(GO) & $\begin{array}{l}\text { a- best-fit slope } \\
\text { b- intercept } \\
\text { best-fit }-r^{2} \\
\text { MBE }\left({ }^{\circ} \mathrm{C}\right) \\
\text { RMSE }\left({ }^{\circ} \mathrm{C}\right)\end{array}$ & $\begin{array}{c}0.46 \\
-10.47 \\
0.43 \\
-0.39 \\
7.66 \\
\end{array}$ & $\begin{array}{c}1.62 \\
-13.98 \\
0.74 \\
-0.41 \\
6.51 \\
\end{array}$ & $\begin{array}{c}1.36 \\
-21.46 \\
0.67 \\
-0.16 \\
6.99 \\
\end{array}$ & $\begin{array}{c}2.64 \\
-69.70 \\
0.30 \\
-0.06 \\
8.69 \\
\end{array}$ & $\begin{array}{l}0.57 \\
2.74 \\
0.52 \\
-0.41 \\
1.05 \\
\end{array}$ & $\begin{array}{c}2.63 \\
-69.78 \\
0.56 \\
-0.08 \\
8.22 \\
\end{array}$ \\
\hline
\end{tabular}

Table 2 b: Parameters of the linear regression (slope $a$, intercept $b$ and coefficient of determination. $r^{2}$ ) as well as MBE and RMSE for the tested parameterization approaches with respect to the measured values for wet periods and dry period, DOYS 55-70, 2004

\begin{tabular}{|c|c|c|c|c|c|c|c|}
\hline Parameterization Approaches & Parameter & $\begin{array}{l}\text { Unstable } \\
\text { Period } \\
\text { (Wet) }\end{array}$ & $\begin{array}{l}\text { Stable } \\
\text { Period } \\
\text { (Wet) }\end{array}$ & $\begin{array}{l}\text { Full- Day } \\
\text { (Wet) }\end{array}$ & $\begin{array}{c}\text { Stable } \\
\text { Period(Dry) }\end{array}$ & $\begin{array}{l}\text { Unstable } \\
\text { Period(Dry) }\end{array}$ & $\begin{array}{c}\text { Full- Day } \\
\text { (Dry) }\end{array}$ \\
\hline TRACY APPROACH(TR) & $\begin{array}{l}\text { a- best-fit slope } \\
\text { b- intercept } \\
\text { best-fit }-r^{2} \\
\text { MBE }\left({ }^{\circ} \mathrm{C}\right) \\
\text { RMSE }\left({ }^{\circ} \mathrm{C}\right)\end{array}$ & $\begin{array}{l}0.86 \\
-4.73 \\
0.69 \\
-0.05 \\
1.47\end{array}$ & $\begin{array}{c}0.79 \\
14.42 \\
0.24 \\
-0.15 \\
3.96 \\
\end{array}$ & $\begin{array}{c}0.97 \\
-7.25 \\
0.63 \\
-0.05 \\
1.16 \\
\end{array}$ & $\begin{array}{c}1.00 \\
-2.43 \\
0.69 \\
-0.04 \\
2.53 \\
\end{array}$ & $\begin{array}{c}-0.40 \\
53.92 \\
0.02 \\
-0.15 \\
3.52 \\
\end{array}$ & $\begin{array}{c}1.94 \\
-6.25 \\
0.68 \\
-0.04 \\
2.43 \\
\end{array}$ \\
\hline FORCE-RESTORED APPROACH(FR) & $\begin{array}{l}\text { a- best-fit slope } \\
\text { b- intercept } \\
\text { best-fit }-r^{2} \\
\text { MBE }\left({ }^{\circ} \mathrm{C}\right) \\
\text { RMSE }\left({ }^{\circ} \mathrm{C}\right)\end{array}$ & $\begin{array}{c}0.65 \\
12.75 \\
0.68 \\
-0.17 \\
2.15 \\
\end{array}$ & $\begin{array}{c}0.66 \\
11.62 \\
0.41 \\
-0.07 \\
2.16\end{array}$ & $\begin{array}{c}0.56 \\
12.95 \\
0.93 \\
-0.05 \\
0.46\end{array}$ & $\begin{array}{c}0.62 \\
11.44 \\
0.85 \\
-0.06 \\
2.91 \\
\end{array}$ & $\begin{array}{c}0.40 \\
14.56 \\
0.44 \\
-0.14 \\
1.99 \\
\end{array}$ & $\begin{array}{c}0.67 \\
8.52 \\
0.89 \\
-0.08 \\
0.88 \\
\end{array}$ \\
\hline LIEBETHAL APPROACH(LI) & $\begin{array}{l}\text { a- best-fit slope } \\
\text { b- intercept } \\
\text { best-fit }-r^{2} \\
\text { MBE }\left({ }^{\circ} \mathrm{C}\right) \\
\text { RMSE }\left({ }^{\circ} \mathrm{C}\right)\end{array}$ & $\begin{array}{c}1.18 \\
6.88 \\
0.90 \\
-0.01 \\
0.71\end{array}$ & $\begin{array}{c}1.62 \\
-31.98 \\
0.93 \\
0.27 \\
1.58\end{array}$ & $\begin{array}{c}0.70 \\
14.21 \\
0.95 \\
-0.03 \\
0.06\end{array}$ & $\begin{array}{c}0.64 \\
16.37 \\
0.86 \\
-0.03 \\
0.79\end{array}$ & $\begin{array}{l}0.56 \\
2.58 \\
0.85 \\
0.03 \\
0.61\end{array}$ & $\begin{array}{l}0.56 \\
9.02 \\
0.67 \\
0.01 \\
0.03\end{array}$ \\
\hline
\end{tabular}

\section{RECOMMENDATION}

The modelling of diurnal pattern of surface temperature using Liebethal approach generally was better with least error values for both stable and unstable atmospheric conditions. The major advantage of this LI approach is that it provides users with conventional mathematical functions and physical interpretation, and this method can easily be adopted in most meteorological stations where soil temperature data are available. However, the limitation of the LI is that the implementation may be limited to few stations in humid tropical region with similar meteorological conditions observed at the NIMEX site.

\section{ACKNOWLEDGEMENT}

The authors appreciate the cooperation of the other members of The Nigerian Micrometeorological
Experiment (NIMEX-1) group, for making the NIMEX-1 project a reality. The NIMEX-1 project was sponsored by International Programmes in the Physical Sciences (IPPS), Sweden; African Regional Centre for Space Sciences and Technology Education, Ile- Ife, Nigeria and National Space Research and Development Agency, Abuja, Nigeria.

\section{REFERENCES.}

[1] Bateni, S. M. and D. Entekhabi, Relative efficiency of land surface energy balance components, Water Resources Research, 48, doi:10.1029/2011WR011357. 2012.

[2] Ma, W., M. Hafeez, U. Rabbani, H. Ishikawa, and Y. Ma Retrieved actual E.T. using SEBS model from Landsat-5 TM data for irrigation area of Australia, Atmos. Environ., 59, 408-414. 2012. 
[3] Liang, S. An optimization algorithm for separating land surface temperature and emissivity from multispectral thermal infrared imagery. IEEE Trans. Geosci. Remote Sens., 39, 264-274. 2001.

[4] Prigent, C, Aires F, Rossow, W. B. Land surface skin temperatures from a combined analysis of microwave and infrared satellite observations for an all-weather evaluation of the differences between air and skin temperatures. J. Geophys. Res., 108, 887-907, 2003

[5] Zeng, X. R, Dickinson, E. M, Barlage Y, Dai G, Wang K., Oleson Treatment of under-canopy turbulence in land Models. J. Climate, 18, 5086-5094. 2005.

[6] Aires, F. C., Prigent, W. B., Rossow, F. T. Temporal interpolation of global surface skin temperature diurnal cycle over land under clear and cloudy conditions, Journal of Geophysical Research, 109, 867 - 889, 2004.

[7] Strack, J. E, Pielke R. A and Adegoke. J. Sensitivity of Approach-Generated Daytime Surface Heat Fluxes over Snow to Land-Cover Changes, Journal of Hydrometeorology, 4(1): 24-42. 2003.

[8] Yang, K, Koike, T and Yang, D Surface flux parameterization in the Tibetan Plateau, BoundaryLayer Meteorol., 116, 245-262. 2003.

[9] Xue, Y, Zeng, F. J., Mitchell, K., Janjic, R. and Rogers, E. The impact of land surface processes on the simulation of the U.S. hydrological cycle: A case study of 1993 US flood using the Eta/SSiB regional approach, Monthly Weather Review, 129: 2833-2860. 2001.

[10] Yang, K., N. T. Koike, H. Fujii, K. Tamagwa, and N. Hirose, Improvement of surface flux parameterizations with a turbulence-related length. Quart. J. Roy. Meteor. Soc., 128, 2073-2087. 2007.

[11] Luce, C. H and Tarboton,D. G. Evaluation of alternative formulae for calculation of surface temperature in snowmelt approaches using frequency analysis of temperature observations. Hydrol. Earth Syst. Sci., 14, 535-543. 2010.

[12] Holtslag, A. A. M. GEWEX atmospheric boundary layer study (GABLS) on stable boundary layers. BoundaryLayer Meteorol118: 243-246. 2006.

[13] Idso, S. B, Aase, J. K. and Jackson, R. D. Net radiation soil heat flux relations as influenced by soil water content variations. Boundary-Layer Meteorol 9: 1131221975

[14] Smith, E. B. and Blackall, R. M. 'The Application of Field-Experiment Data to the Parameterization of the Dispersion of Plumes from Ground-level and Elevated Sources, in C. J. Harris (ed.), , Academic Press 42(6), 851-862. 1979 .

[15] Holtslag A. A. M. and Van Ulden A. P Simple estimates of night-time surface fluxes from routine weather data. J. Climate Appl. Meteor., 22,517-529. 1983.

[16] Liebethal, C. and Foken, T. Evaluation of six parameterization approaches for the ground heat flux.
Theor. Appl. Climatol, Climatology A. vol. 8, 43-56. 2007.

[17] Tracy, C. R., Ven Berkum, F. H. Tsuji, J S, Sterenson, R. D, Nelson J. A, Bernes, B. M and Huey, R. B. Errors resulting from linear approximations in energy balance equation J. Thermo Biol, 9: 261 - 284. 1984.

[18] Gao, Z., Chae, N., Kim, J., Hong, J., Choi, T. and Lee, H. Approaching of surface energy partitioning, surface temperature and soil wetness in the Tibetan prairie using the Simple Biosphere Approach 2 (SiB2). Journal of Geophysical Research, 109, 2004

[19] Göttsche, F. M. and Olesen, F. S. Approaching of diurnal cycles of brightness temperature extracted from METEOSAT data. Remote Sensing of Environment, 76, 337-348. 2001.

[20] Adeniyi, M. O. and Nymphas, E.F. Estimation of bare soil surface temperature from air temperature and soil depth temperature in a tropical station. International Journal of Natural and Applied Sciences 7 (4), 429437. 2009.

[21] Jegede, O. O, Okogbue, E.C and Balogun, E. E Proceedings of the workshop and the Nigeria Micrometeorological experiment 1,15 July, Ile-Ife, Nigeria. 2004.

[22] Mauder, M. Jegede, O. O, Okogbue, E. C, Winmer, F and Foken $\mathrm{T}$ Surface Energy balance measurement at a tropical site in West Africa during the transition from dry to wet season. Theor. Appl. Climatol.88. 171-183. 2006.

[23] Essenwanger, 0. M. Classification of climates, world survey of climatology 1C, general climatology. Elsevier, Amsterdam, 102 pp, 10,. 2001.

[24] Foken, T. Angewandte Meteorologie. Mikrometeorologische Methoden. Springer, Heidelberg, p 289, 2004.

[25] Otunla, F. A and Oladiran, O. A, Evaluation of Soil Thermal Diffusivity Algorithms at Two Equatorial Sites In West Africa Annals Of Geophysics, 56, 1, 2013,

[26] Stull, R. B. An introduction to boundary layer meteorology. Kluwer Academic Publishers, Dordrecht, pp 262-263, pp Evans, M, Hastings, N. and Peacock, B. Statistical distributions, Wiley, New York, pp 56-67. 1988. 1993.

[27] Evans M, Hastings N and Peacock B Statistical distributions, Wiley, New York, pp 56-67. 1993.

[28] Campbell, G. S. and Norman, J. M. An Introduction to Environmental Biophysics, 2nd ed. Springer, New York. 286 pp. 1998.

[29] Monteith J. L. Principles of Environmental Physics, Edward Arnold, London, 1973.

[30] Lin, J. D. On the force-restore method for prediction of ground surface temperature. Journal of Geophysical Research 85 (C6), 3251-3254. 1980. 